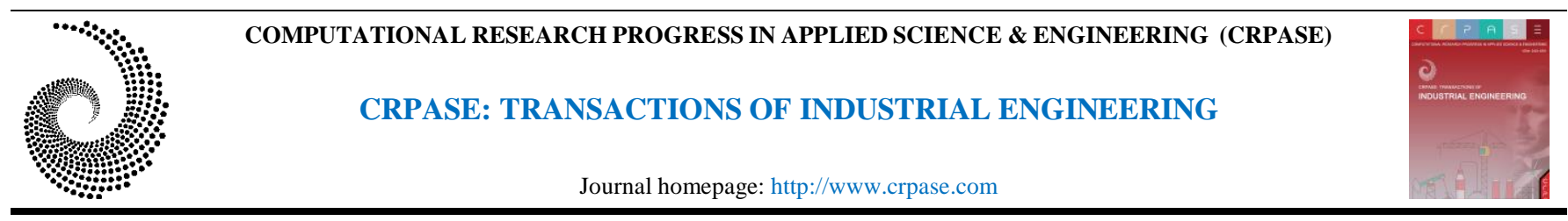

\title{
A Short Communication: An Economic Assessment of Offshore Natural Gas Transferring Pipeline
}

\author{
Mohammad Yazdi* \\ Faculty of Engineering \& Applied Science, the Memorial University of Newfoundland, St. John's, NL, Canada
}

\begin{tabular}{ll}
\hline Keywords & Abstract \\
\cline { 1 - 3 } $\begin{array}{l}\text { Risk assessment, } \\
\text { Fault tree analysis, }\end{array}$ & $\begin{array}{l}\text { The pipelines play an essential role in safely delivering oil and gas products over distances } \\
\text { Pipeline, }\end{array}$ \\
Marine. & $\begin{array}{l}\text { throughout the world and continually work overtime. However, the pipelines as the } \\
\text { component of the system would fail in the period. The consequences of any failure may face } \\
\text { the approach to the catastrophic loss and damage environmental and reputation. Thus, } \\
\text { decision-makers need to maintain the pipeline for a specific time. In this study, the aim is to } \\
\text { review the economic assessment of offshore natural gas transferring pipelines. It highlights } \\
\text { the main reasons for the pipelines failures, asset integrity management system requirement, } \\
\text { risk assessment, and other risk management. }\end{array}$ \\
\hline
\end{tabular}

\section{Introduction}

As the critical infrastructures of marine and offshore industrial sectors, the pipelines are prone to a high failure rate, which enface the system to considerable loss [1-4]. The potential threats to the pipeline integrity are classified into the following categories, (i) different types of corrosion (e.g., internal, external, pitting, $\mathrm{CO}_{2}$, etc.) [5-8], (ii) third-party damage (e.g., earth moving equipment, etc.) [9-11], (iii) stress corrosion cracking [12,13], (iv) geotechnical failures (e.g., landslide movement, etc.), and (v) other types of pipeline failures such human error $[14,15]$. Many proactive and reactive measurement tools; however, hazards and their corresponding effects $[16,17]$. Besides, any pipeline failures can impact both environment and the public significantly. For example, the cost of cleaning up after release is very high. The failure would shut down the system the products would not be delivered on time. Thus, such concerns are asking to have proper asset integrity management. The national energy board of Canada issued a robust guideline for the in-line inspection process of the pipelines considering different pipeline failures across the country. In the US, the "Bill HR 1489" indicated that "all pipelines, gas, and liquid, identified in environmentally sensitive and high-density populated areas be inspected using smart pigs". In this regard, the well-planed and reliable asset integrity management programs would assist in minimizing having many regulations for the system and help decision-makers increase the pipeline's integrity without enhancing the pipeline operating and maintenance costs. In addition, any integrity management should plan to minimize the impact of failure on public, environmental, and operating disruptions.

\section{What Is Pipeline Integrity Management?}

This management utilizes an engineering approach to develop different programs by analyzing, detecting, assessing, evaluating, and eliminating the risks of pipeline failure. The idea behind pipeline integrity management is preventing the asset integrity challenges within the significant impact on the environment, safety, and repreparation of the system. This is the four-step-based

* Corresponding Author: Mohammad Yazdi
E-mail address: Mohammad_yazdi@live.com

Received: 15 October 2021; Revised: 13 November 2021; Accepted: 6 December 2021

https://doi.org/10.52547/crpase.7.4.2409

Academic Editor: Mohammad Nikookar

Please cite this article as: M. Yazdi, A Short Communication: An Economic Assessment of Offshore Natural Gas Transferring Pipeline, Computational Research Progress in Applied Science \& Engineering, CRPASE: Transactions of Industrial Engineering 7 (2021) 1-4, Article ID: 2409. 
program, including (i) pipeline assessment, (ii) inspection management, (iii) detect and repair assessment, and (iv) rehabilitation and maintenance management [18]. This paper is focused on the pipeline assessment.

\section{- $\quad$ Pipeline assessment}

The most critical task in pipeline integrity management is understanding the pipelines' hazards, their corresponding likelihood, and consequences. The hazards in pipelines are categorized into corrosion, contact damage, stress cracking corrosion, soil type and instability, material defects, construction practices, and operating problems. In addition, the consequence can be fatalities, injuries, explosions, fire, property damage, pollution, revenue loss, product loss, reputation damage, and impact on system prestige.

The hazards prevention and consequence mitigations connected with the pipeline's failure are an "active process" and must be considered during all design, operation, and construction processes. The risk assessment procedure approximates both safety and economic risks. One of the main helpful risk assessment tools is fault tree analysis (FTA), in which it could estimate the probability of failure by root cause analysis [18-23]. In this paper, an FTA is developed according to the existing literature, and to the best of the authors' knowledge, and presented in Figure 1 regarding fire and explosion in offshore gas transferring pipeline.

The probability of failure as fire and explosion in an offshore pipeline is critical to assessing system safety and economic risks. The data used to estimate the probability of a top event can be obtained objectively (i.e., handbook reliability data) [24] or subjectively (i.e., using fuzzy-based approaches) [25-27]. In addition, the objective data can be obtained from operating conditions and company records within supplemented data and experience. The FTA provides insights into the contributions of the failure into the probability of fire and explosion gas transferring offshore pipeline. In this regard, the probability of loss can be further determined as the combination of the probability of fire and explosion and the probability of the site being occupied.

Moreover, the risks in terms of safety regarding fire and explosion of the pipeline depending on the pipeline's physical location. This study assumes that the probability of the basic event in FTA is obtained in both an objective and subjective manner. In this regard, the economic risk assessment would be derived as the combination of the probability of fire and explosion and the corresponding consequences. The diagram is depicted in Figure 2.

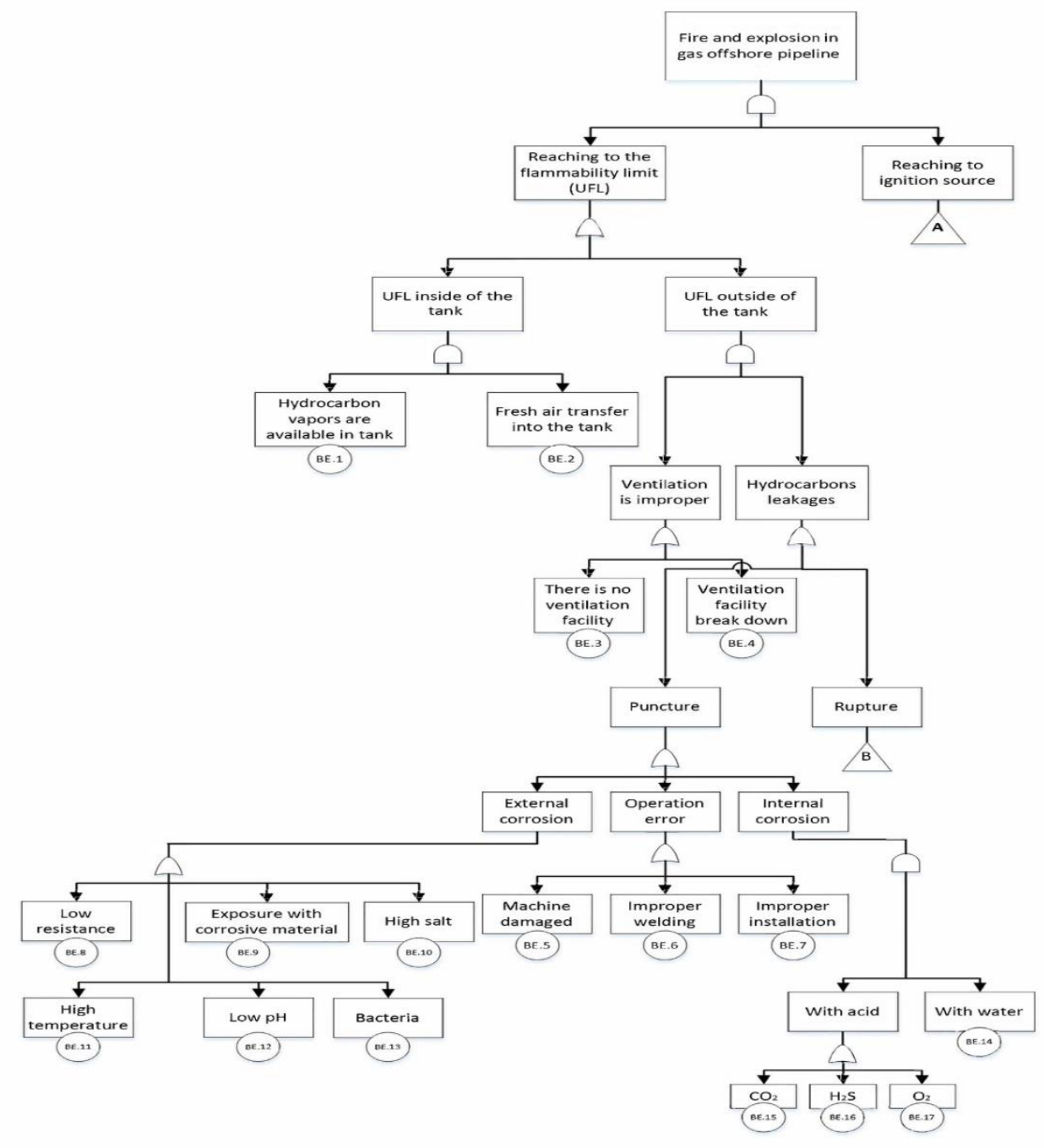



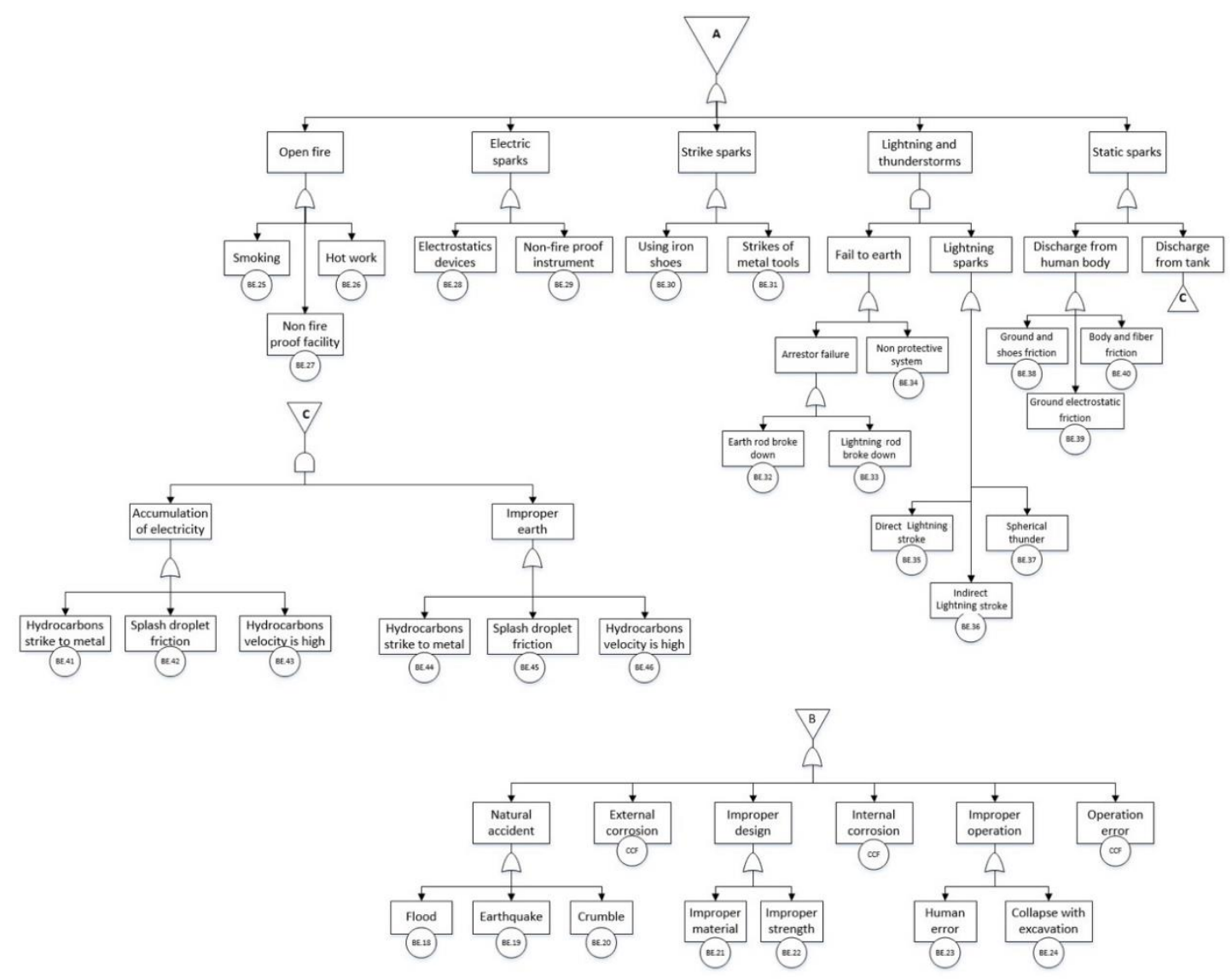

Figure 1. The FTA of fire and explosion in offshore gas transferring pipeline

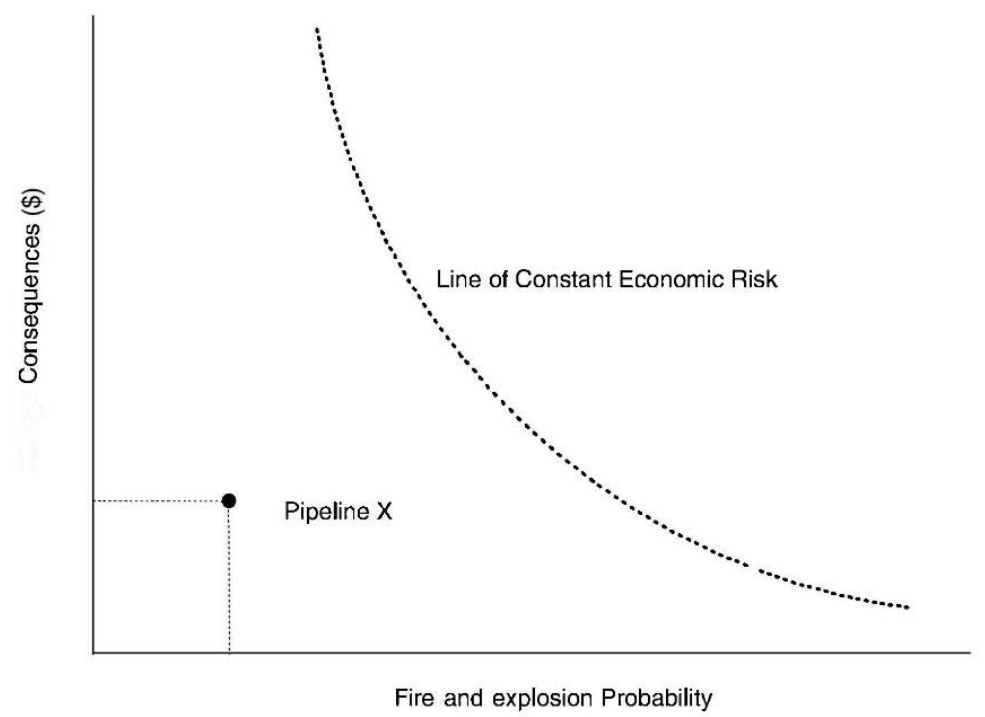

Figure 2. The economic risk assessment of gas transferring pipeline (modified after [18])

\section{Conclusions}

In this paper, a brief economic assessment of offshore natural gas transferring pipelines is discussed. An FTA is developed for a vital pipeline failure as fire and explosion.

primary input into the next steps of asset integrity management.
In FTA, all contributing factors as basic events which lead to the top event are identified. The probability of the basic events is determined in both objective and subjective ways. Finally, the economic risk assessment of the gas transferring pipeline is examined. These results would be used as the 


\section{References}

[1] S. Adumene, F. Khan, S. Adedigba, S. Zendehboudi, H. Shiri, Dynamic risk analysis of marine and offshore systems suffering microbial induced stochastic degradation, Reliab. Eng. Syst. Saf. 207 (2020) 107388.

[2] S. Adumene, F. Khan, S. Adedigba, S. Zendehboudi, Offshore system safety and reliability considering microbial influenced multiple failure modes and their interdependencies, Reliab. Eng. Syst. Saf. (2021) 107862.

[3] M. Yazdi, F. Khan, R. Abbassi, Microbiologically influenced corrosion (MIC) management using Bayesian inference, Ocean Eng. (2021).

[4] M. Yazdi, K.A. Adesina, O. Korhan, F. Nikfar, Learning from Fire Accident at Bouali Sina Petrochemical Complex Plant, J. Fail. Anal. Prev. (2019).

[5] S.P. Kuniewski, J.A.M. van der Weide, J.M. van Noortwijk, Sampling inspection for the evaluation of time-dependent reliability of deteriorating systems under imperfect defect detection, Reliab. Eng. Syst. Saf. 94 (2009) 1480-1490.

[6] M. Yazdi, O. Korhan, S. Daneshvar, Application of fuzzy fault tree analysis based on modified fuzzy AHP and fuzzy TOPSIS for fire and explosion in the process industry, Int. J. Occup. Saf. Ergon. 26 (2020) 319-335.

[7] S. Haladuick, M.R. Dann, Risk-Based Maintenance Planning for Deteriorating Pressure Vessels With Multiple Defects, J. Press. Vessel Technol. Trans. ASME. 139 (2017).

[8] M.D.C. Moura, I.D. Lins, E.L. Droguett, R.F. Soares, R. Pascual, A multi-objective genetic algorithm for determining efficient risk-based inspection programs, Reliab. Eng. Syst. Saf. 133 (2015) 253-265.

[9] G.-J. Jiang, H.-X. Chen, H.-H. Sun, M. Yazdi, A. Nedjati, K.A. Adesina, An improved multi-criteria emergency decision-making method in environmental disasters, Soft Comput. (2021).

[10] M. Yazdi, Risk assessment based on novel intuitionistic fuzzy-hybrid-modified TOPSIS approach, Saf. Sci. 110 (2018) 438-448.

[11] Y. Guo, X. Meng, D. Wang, T. Meng, S. Liu, R. He, Comprehensive risk evaluation of long-distance oil and gas transportation pipelines using a fuzzy Petri net model, J. Nat. Gas Sci. Eng. 33 (2016) 18-29.

[12] F. Ayello, S. Jain, N. Sridhar, G.H. Koch, Quantitive Assessment of Corrosion Probability-A Bayesian Network Approach, Corrosion. 70 (2014) 1128-1147. https://doi.org/10.5006/1226.

[13] M. Zamanzadeh, G.T. Bayer, A.K. Chikkam, Cathodic
Protection, Coatings That Shield Cathodic Protection, Stress Corrosion Cracking and Corrosion Assessment in Aging Coated Pipe Lines and Buried Utility Structures, Corros. 2018. (2018).

[14] M. Yazdi, N.A. Golilarz, A. Nedjati, K.A. Adesina, An improved lasso regression model for evaluating the efficiency of intervention actions in a system reliability analysis, Neural Comput. Appl. (2021).

[15] F.I. Khan, M.R. Haddara, Risk-based maintenance of ethylene oxide production facilities, J. Hazard. Mater. 108 (2004) 147-159.

[16] M. Rausand, Risk Assessment: Theory, Methods, and Applications, Wiley, 2011.

[17] M. Yazdi, Ignorance-aware safety and reliability analysis: A heuristic approach, Qual. Reliab. Eng. Int. 36 (2020).

[18] M. Mohitpour, H. Golshan, A. Murray, Pipeline Design \&amp; Construction: A Practical Approach, Third Edition, ASME Press, 2007.

[19] M. Yazdi, S. Kabir, M. Walker, Uncertainty handling in fault tree based risk assessment: State of the art and future perspectives, Process Saf. Environ. Prot. 131 (2019).

[20] M. Yazdi, S. Kabir, Fuzzy evidence theory and Bayesian networks for process systems risk analysis, Hum. Ecol. Risk Assess. 26 (2020) 57-86.

[21] M. Yazdi, F. Nikfar, M. Nasrabadi, Failure probability analysis by employing fuzzy fault tree analysis, Int. J. Syst. Assur. Eng. Manag. 8 (2017) 1177-1193.

[22] A. Shahriar, R. Sadiq, S. Tesfamariam, Risk analysis for oil \& gas pipelines: A sustainability assessment approach using fuzzy based bow-tie analysis, J. Loss Prev. Process Ind. 25 (2012) 505-523.

[23] M. Rausand, A. Hoyland, System Reliability Theory: Models, Statistical Methods, and Applications, (2004) 664.

[24] OREDA, Offshore Reliability Data Handbook, 4th ed., Trondheim, 2015.

[25] M. Yazdi, Improving failure mode and effect analysis (FMEA) with consideration of uncertainty handling as an interactive approach, Int. J. Interact. Des. Manuf. 13 (2019) 441-458.

[26] M. Yazdi, Acquiring and Sharing Tacit Knowledge in Failure Diagnosis Analysis Using Intuitionistic and Pythagorean Assessments, J. Fail. Anal. Prev. 19 (2019) 369-386.

[27] M. Yazdi, F. Nikfar, M. Nasrabadi, Failure probability analysis by employing fuzzy fault tree analysis, Int. J. Syst. Assur. Eng. Manag. 8 (2017) 1177-1193. 